\title{
Causative in Sasak: A Mechanism of Valency Increase
}

\author{
Nurul Azizah \\ Udayana University, Bali, Indonesia \\ Ketut Artawa \\ Udayana University, Bali, Indonesia \\ Ni Luh Ketut Mas Indrawati \\ Udayana University, Bali, Indonesia \\ Made Sri Satyawati \\ Udayana University, Bali, Indonesia
}

\begin{abstract}
This study discusses the formation of causatives based on the criteria proposed by Dixon (2012). Pertain to the mechanism of valency increasing, it is found that causative construction in Sasak Kuto-Kute dialect covers two forms: morphological and lexical. Morphological causative involves the process of adding confix $N$-ang/in and affix -in to the non-causative base verb, whilst, the lexical causative uses the causative verb mate 'died/killed'. Furthermore, it was found that the formation of causative from intransitive verbs can be done by moving the original $S$ to $O$ position in the causative construction, which is morphologically marked on the verb, and also using different verbs with the same meaning to form the causative construction which is followed by the transfer of the original $S$ to $O$ position. For transitive verbs, the formation can be done through the use of affixes with the original $A$ and original $O$ both becoming $O 1$ and $O 2$. Last, the causative construction in the dialect semantically involves five semantic parameters, namely transparency, naturalness, intention, involvement, and control.
\end{abstract}

Index Terms - Sasak, causative, valency increase

\section{Introduction}

Causative is known as a way that can be used to add an argument on sentence structures (Dixon and Aikhenvald, 2000, p. 20). The addition of an argument in a causative is employed in A function in the syntactic structure (Haspelmath and Müller-Bardey, 2001, p. 11). According to Bybee (1985, p. 29), causative is the most common valence-changing category in her world-wide sample of 50 languages. The syntax and semantics of causatives have been studied extensively, cf. Shibatani (ed.) 1976b, Comrie 1985, Baker 1988, Song 1996, Dixon 2000 and many more. Many languages can only construct causative from intransitive verbs such as in Lezgian (Haspelmath, 1993a), however, some languages have causatives derived from transitive verbs (Haspelmath and Müller-Bardey, 2001, p. 12)

Causative construction sometimes described as a construction involving 'two events'. According to Goddard (1998, p. 226), causative can be defined as an expression in which an event (a caused event) is described as occurring because someone caused something or because something happened. Shibatani (1976b, p. 1) specifies causative as something related to 'events that cause' and 'caused events'. Meanwhile, Frawley (1992, p. 159) identifies causative as 'events that trigger' and 'results'. Slightly different from definitions proposed the linguists, Dixon (2012, p. 241) explains the idea of 'secondary concepts' which involve semantic modifications of lexical verbs. The secondary concept can be realized through affixation, other morphological processes or separate words. Examples of this concept can be found in the secondary-C type verbs, namely, make and help. When using both verbs in a basic clause, an argument in the form of causer/helper can be added as A. The addition of the argument is the formation of a causative which involves the specification of additional arguments of causer in the basic clause. The causer is someone or something (which can be an event or a state) that starts or controls an activity, which is a property of the syntactic-semantic A function (transitive subject) (Dixon, 2012, p. 241). To this, the main purpose of this article is to discuss the process of constructing causatives in Kuto-Kute dialect using the linguistic typology approach proposed by Dixon (2012). Through the 70 verbs meaning questionnaire, the obtained data is then identified, grouped and analyzed descriptively.

\section{Methodology}

This research is limited to the causatives in Sasak Kuto-Kute dialect using the list of 70 meanings proposed by Malchukov and Comrie (2010) and applying the theory of linguistic typology from Dixon (2012) to the intransitive and 
transitive of AV (actor voice) sentences. The verb list is a direct adoption of the 70 verbs listed in the 'Leipzig Valency Classes Project'. The reason for the direct adoption of these particular verbs is because the meanings of the 70 verbs have been universally tested in various languages. The verbs are provided with their semantic meanings and examples of sentences in English. The words and sentences are then translated into Indonesian and Kuto-Kute dialect, in which the results have been double-checked by Indonesian translators and several linguists of the dialect related to their compatibility with English as the source language. Out of 70 English verbs, the translation only resulted in 66 verbs in Kuto-Kute dialect. This is due to 8 English verbs are translated into 4 verbs ('sit' and 'sit down' = tokol; 'fear' and 'frighten' = takut; 'beat' and 'hit' = padeq; 'fill' and 'load' = isin). In its implementation, the verb list is used to gain the data in the form of sentences from the native speakers of Kuto-Kute dialect, which was carried out by looking for examples of the Indonesian sentences in that dialect along with their alternative forms. Among the forms, the verbs with causatives are analyzed on the movements of the arguments and suffixes attached to the verbs. The data are glossed per morpheme and followed by free translations.

\section{Discussion}

Every language has its way of expressing causative. Several alternatives can be used to provide a formal marking in causative construction. The most common method is the morphological process applied to the core verb. Another way is combining two verbs in one predicate, either as a serial verb construction or in a form of other construction. Dixon (2012, p. 242-280) classifies the methods into three main groups namely formal mechanism, syntactic and semantic mechanisms.

\section{A. Formal Mechanism}

According to Dixon (2012, p. 242) formal mechanism describes a variety of causative forms. Starting from the morphological process applied to the verbs of the basic clause, causative involving two verbs forming a single predicate/serial verb construction, periphrastic causatives, causatives that see lexical pairs existing in causal relationships and in ambitransitive verbs of type $S=O$ (lexical causatives), to causatives in the form of a causative effect occurred through the exchange of auxiliaries that follows a lexical verb (exchanging auxiliaries). Within the data, the formation of causative as a valency increase mechanism through formal mechanism only includes 2 forms namely morphological causative and lexical causative.

1. Morphological Causative

Morphological process or causative morphology is a causative structure in which its predicate is filled with verbs that are formed from morphological processes in such a way to produce causative verbs that have morphological characteristics. The morphological process may include internal changes such as consonant repetition, reduplication, vocal extension and the like, or various affixations. In some languages, the same affix used in causative verbs can also be attached to the bases of adjective or noun categories (Dixon, 212, p. 242). From the given definition, it can be inferred that causative formed through the morphological process involves the process of affixation to the non-causative bases. In Kuto-Kute, there are several examples of sentences in the data that fall into this category.

(1a) Susi n-elep-ang kapal nelayan

Susi ACT-sink-CAUS boat fisherman

'Susi sank the fisherman's boat'

(2a) $K u \quad$ ng-iroq-ang ia

1SG ACT-sedih-CAUS 3SG

'I made him sad'

(3a) Ia m-aula-ng jaranleq baranya

3SG ACT-run-CAUS horse PREP stall-POSS

'Dia made the horse ran from his stall'

(4a) Azkar ny-akit-in manuq nu

Azkar ACT-hurt-CAUS chicken DEF

'Azkar hurt the chicken'

(5a) $K u \quad$ nyet-in ager-ager nu

1SG Øcold-CAUS jelly DEF

'I made the jelly cold'

Sentences (1a) - (5a) are causative that use transitive verbs. These sentences come from the intransitive clauses below with the addition of A argument thereby increasing the valence of the initial predicate. The valency increase is marked by CAUS markers on its verbs. The original clauses are as follow:

(1b) Kapal nelayan nu telep

Boat fisherman DEF sink

'The fisherman's boat sank'

(2b) Ia iroq

3SG Øsad

'S/he is sad' 
(3b) Jaran nu $\quad$ m-aulaq

Horse DEF ACT-run

'The horse ran'

(4b) Manuq nu sakit

Chick DEF sick

'The chicken is sick'

(5b) Ager-ager nu mulai nyet

Jelly DEF start cold

'The jelly started to get cold'

From the examples above it is to be seen that the affixes that can be used to form causative verbs are the affixes $N$-ang/in and -in. These affixes can be attached to non-causative bases either to verbs (telep 'drowned' and paulaq 'run'), or other word classes such as adjectives (iroq 'sad', sakit 'sick' and nyet 'cold'). By adding these two affixes, transitive causative derivations are formed functioning as predicates.

In sentence (1a) the verb nelepang 'drown' is formed by adding prefix $n$ - as an active marker (ACT) with suffix -ang as a causative marker (CAUS) attached to the base telep 'sink'. Similar to sentence (1a), sentences (2a) and (3a) also use suffix -ang (with - $n g$ as an allomorph) attached to iroq 'sad' and paulaq 'go' to form transitive causative verbs. Differ to the two sentences, sentences (4a) and (5a) take suffix -in as the causative marker with prefix $N$-attached to the word sakit, functioning as a predicate. Meanwhile, the word nyet takes the form $\varnothing$ (affixless). These affixes can add A argument to intransitive clauses. For example, when the verb telep 'sink', which is an intransitive with only one single argument (S), gets an $N$-ang affix and forms nelepang 'drown', the verb transforms into a transitive verb that requires two core arguments; namely A that precedes the verb and makes the grammatical subject (S) as $\mathrm{O}$ that follows the verb.

2. Lexical Causative

Other causative constructions found in the data are lexical causative. Lexical causative is a form of causative that does not involve morphological processes or separate causative verbs (Dixon, 2012, p. 247). In the causative clause, the predicate takes a causative verb. Pertain to the increase of verb valence, in Kuto-Kute there are only two examples of clauses that fall into this category.

(6a) Ular nu mate

Snake DEF die

'The snake died'

(7a) Musuhnya mate

Enemy-POSS die

'His enemy died/killed'

Data (6a) and (7a) are examples of intransitive lexical causative clauses with one single argument occupying a position as a S. Looking closely, all the nouns (ular and musuh) functioning as $\mathrm{S}$ have specific roles, namely as $\mathrm{P}$ (patient). Adding core arguments to the clauses above to increase the verbs' valance can be done by adding A arguments, positioned before the verbs. Through the addition of A arguments as the doers, the S, which initially precede the verbs, move into the position after the verb and act as O. The following constructions are derived from the two previous clauses:

(6b) Amaq mate-ang ular nu

Father Økill-TRAN snake DEF

'Father killed the snake'

(7b) Ku m-binoq musuhnya kadu pemolong

1SG ACT-kill enemy-POSS using stick

'I killed his enemy with a stick'

The process of adding A argument (Amaq 'father' and $k u$ 'I') as in (6b) and (7b), takes place as the initiator of the action that causes final states as in (6a) and (7a). The addition of these arguments has changed the intransitive verbs into transitive or in other words, increased the valency of the verb, which initially only has one single argument (S) into verbs with two core arguments (A and $\mathrm{O}$ ). When the object is an animal, the verb mate 'die/kill' can be used in a transitive derivation form. However, when the object is a human, the transitive form must be taken from the base binoq 'kill'. In Indonesian, the intransitive form of the word bunuh 'kill' is terbunuh 'killed', but the form 'killed' in this dialect does not exist, which means the dialect does not have the lexical 'killed'. To express the same meaning semantically, the dialect uses the lexical mate 'die/dead'.

\section{B. Syntactic}

Syntactic causative, in this case, refers to the various possible ways of marking that can be employed in various forms of causatives (Dixon, 2012, p. 250). Syntactic causative focuses on how certain type of verbs form causative structures. In English, the intransitive clause of John tripped can form a causative clause of Marry tripped John. Unfortunately, this does not apply to transitive clauses. However, according to Dixon (2012), there is a situation in English where transitive causatives can be formed only by changing the position of the constituents. For example, the use of secondary A-verbs of start in the clause The maid started to clean the bathroom at 10 o'clock can form a causative clause by adding a new A (cause) and placing it before the verb. The original $\mathrm{A}$ is then being placed between 
the verb start and the next verb (clean) so that it becomes Mother started the maid cleaning the bathroom at 10 o'clock. The addition of the new A to the transitive clause and making it into a transitive causative clause does not add to the semantic role of the clause, it is only a semantic modification. The following will explain the causative formation syntactically in Kuto-Kute by looking at the verb specifications.

Almost all causative mechanisms apply to intransitive verbs. In almost all languages it is found that when intransitive clauses form causative clauses the original $\mathrm{S}$ becomes $\mathrm{O}$ from the causative construction. However, there are other languages (for example, Japanese and Hungarian) that use other markings for the original S so that it gives a different semantic meaning. Let's look at the data found in Kuto-Kute.

\section{(8a) Bannya te-goloq}

Wheel-POSS ACT-roll

'His wheel is rolling'

(8b) Rahmat ne-goloq-ang ban kon rorong

Rahmat ACT-roll-CAUS wheel on road

'Rahmat rolled the wheel on the road'

(9a) Jaminya gar

Rice straw-POSS Øburn

'His rice straw is burnt'

(9b) Abet ny-edut jaminya

Abet ACT-burn rice straw-POSS

'Abet burnt his rice straw'

Data (8a) and (9a) are intransitive clauses with their pairs (8b) and (9b) as their causatives. It can be seen that the original $\mathrm{S}$ in the intransitive clauses are demoted into $\mathrm{O}$ in the causatives. The two original $\mathrm{S}$ (ban and jami) semantically act as patients. The verb goloq 'roll' in (8a) is an ambitransitive verb type with $\mathrm{S}=\mathrm{O}$. Differ to (8), in (9) there is a change on the use of verbs in the causative. Although both verbs ( $g a r$ and sedut) have the same meaning as 'burn', as seen in the example above, the verb gar is a purely intransitive verb while sedut is a purely transitive verb. Semantically, the two verbs have different meanings where gar is accidental while sedut is done consciously/intentionally. Based on the above examples, it was found that the formation of causative from intransitive verbs can be formed by moving the original $\mathrm{S}$ to $\mathrm{O}$ position in the causative, which is morphologically marked on the verb, and also using different verbs with the same meaning to form the causative which is followed by the demotion of the original $\mathrm{S}$ to $\mathrm{O}$ position.

Differ to intransitive verbs, according to Dixon (2012, p. 256) there are 5 types of transitive causatives namely: (i) Specific markers for the causer, (ii) The causer maintains the marking for A, (iii) The original A uses the O marker while the original $\mathrm{O}$ retains the markers, (iv) The original $\mathrm{A}$ becomes the new $\mathrm{O}$ and the original $\mathrm{O}$ exits the core, and (v) The original $\mathrm{O}$ remains $\mathrm{O}$ while the original A leaves the core. The five types can be summarized in the following table:

TABLE 1

TRANSITIVE CAUSATIVE

\begin{tabular}{|l|l|l|l|}
\hline Type & Causer & Original A (causee) & Original O \\
\hline (i) & A & Special marking & O \\
\hline (ii) & A & Retains A marking & O \\
\hline (iii) & A & has O-marking & has O-marking \\
\hline (iv) & A & O & non-core \\
\hline (v) & A & non-core & O \\
\hline
\end{tabular}

In type (i), there are special markings used only for the causee in the causative construction. In type (ii), both the causer and the original A get A-marking. In type (iii), original A and original O both receive O-marking. In type (iv), the original $\mathrm{A}$ becomes $\mathrm{O}$ while the original $\mathrm{O}$ receives a non-core marker, and in type (v), the original $\mathrm{O}$ remains as it is while the original A receives a non-core marker. Type (i) and (ii) are generally relatively rare in various languages, but the type (iii) is the type most frequently used. The use of types (iv) and (v) fall into moderate frequency.

The five types are techniques for forming causative using transitive verbs. Concerning the matter, within the data, only one was found deriving from transitive verb. See the following example:

(10a) Bai nu ng-unut bawang

Baby DEF ACT-smell onion

'The baby smelled the onion'

(10b) Inaq ng-unut-in bainya bawang

Mother ACT-smell-CAUS grandchild-POSS onion

'Mother made the grandchild smelled the onion'

Causative formation using transitive verbs can be done in through the morphological process as seen in (10). (10a) is the underlying clause, while $(10 \mathrm{~b})$ is the derived causative. Through the examples above, it can be seen that the formation of the causative in (10b) is composed using type iii, where the original $\mathrm{A}$ and the original $\mathrm{O}$ both become $\mathrm{O}$.

In (10a), the position of the original $\mathrm{A}$ is filled with bai 'grandchild', while the original $\mathrm{O}$ is occupied by bawang 'onion'. The addition of a new A as a causee for the underlying clause, which is filled by Inaq 'mother', has changed 
the position of the original A and the original O. In (10), the original A that preceded the verb is now following the verb, and the original $\mathrm{O}$ positioned after the verb is now occurring after the original $\mathrm{A}$. The original $\mathrm{A}$ and the original $\mathrm{O}$ both play the role of $\mathrm{O}$, but in this case, it can be said that the original A plays the role of $\mathrm{O} 1$ while the original $\mathrm{O}$ plays the role of $\mathrm{O} 2$. The causative form in (10b) is marked by affix -in.

\section{Semantic}

Some languages may have two or more causatives that involve a variety of different formal mechanisms or markings on different causee. However, there will always be semantic differences involving one or several of the nine semantic parameters. The lesser the causative formation mechanism a language has, the greater the semantic range is (Dixon, 2012, p. 269).

Semantic causative is the formation of causative by referring to 9 semantic parameters. The nine parameters are:

1. State/Action: whether a causative mechanism only applies to state verbs or also to action verbs.

2. Transitivity: does a causative mechanism only apply to intransitive verbs, or both; intransitive and transitive, or to all verbs; intransitive, transitive and extended transitive (ditransitive).

3. Control: whether the causee has complete control of the activity or not.

4. Volition: whether the causee does it willingly or unwillingly.

5. Affectedness: whether the causee is only partially or fully affected by the activity.

6. Directness: whether the causer acts directly or indirectly.

7. Intention: whether the causer achieves the result intentionally or accidentally.

8. Naturalness: whether the activity occurs naturally (causer only initiates a natural process) or is the result only achieved with effort (possibly with violence).

9. Involvement: whether the causer is involved or not in the activity.

The semantic-related discussion in this sub-section will involve examples in the previous sub-sections. In Kuto-Kute, it was found that the formal mechanism employed in the formation of causatives involves several semantic parameters.

For morphological mechanisms, from the examples of sentences in (1) - (5), (8) dan (10) in terms of their transitivity it is proven that morphological mechanism can only be used for intransitive and transitive verbs only. Not only that, in terms of intention the results of Kuto-Kute causatives are generally achieved intentionally. This is because in terms of its general nature, the meaning of the causatives indicates that the activity occurs unnaturally or it is done intentionally. For the example in (10b), the activity is performed by the mother for her grandchild not to be disturbed by evil spirits. Related to involvement, the semantic meaning of (2), (3), (4), (5), (8), dan (9) all refer to the involvement of the causee in all activities, but specifically for data (1) with the verb nelepang 'drowning', the sentence can be interpreted as Susi was involved in the action but it can also mean that Susi ordered her men to take the action (not involved in the action). From this analysis, it can be concluded that the formation of the Kuto-Kute causatives through morphological mechanism involves at least four semantic parameters, namely transitivity, intention, naturalness, and involvement.

For lexical causative, it was found that its formation involved at least four semantic parameters. The four parameters are transitivity, intention, naturalness, and control. From data in (6) and (7) it can be seen that Kuto-Kute lexical causatives only use intransitive causative verbs to provide purposefully achieved results. Also, the naturalness indicates that the activities of the clauses ((6) and (7)) occur unnaturally (intentionally) and in this case, the causee has full control because as it has been said that the action shown is done intentionally. Based on the overall data analysis by applying 9 semantic parameters proposed by Dixon (2012) as a reference, it is known that the formation of causatives in Kuto-Kute involves five semantic parameters namely transitivity, naturalness, intention, involvement and control.

\section{Conclusion}

Through the analysis carried out on to the causatives, it was found that the formation of Kuto-Kute causatives as a mechanism of valency increase can be based on three main groups, namely formal, syntactic and semantic mechanisms. The formation of causative through formal mechanism only includes 2 forms: morphological causative and lexical causative. Causatives formed through morphological processes involve the process of affixation to the non-causative bases. The affixes are affixes $N$--ang/in and -in which can be attached to non-causative bases of verbs, adjectives or nouns. For lexical causative, its formation uses only verbs with causative meanings. The verb found in the data is the mate "died/killed".

Syntactic causative focuses on how certain type of verbs form causative constructions. From the data analysis, it was found that the formation of causative from intransitive verbs can be formed by moving the original $\mathrm{S}$ to $\mathrm{O}$ position in the causative, which is morphologically marked on the verb, and also using different verbs with the same meaning to form the causative which is followed by the demotion of the original $\mathrm{S}$ to $\mathrm{O}$ position. For causatives using transitive verbs, in Kuto-Kute, the formation can be done through the morphological process. Based on the criteria proposed by Dixon (2012), the formation of causatives with transitive verbs in Kuto-Kute is performed with type iii; the original A and the original $\mathrm{O}$ both become $\mathrm{O}$.

Meanwhile, semantic causative sees the formation of causatives by referring to 9 semantic parameters proposed by Dixon (2012) for the three forms of causatives found in the formal mechanism. From the observation, it was found that the formation of Kuto-Kute causatives through morphological mechanism involved at least four semantic parameters, 
namely transitivity, intention, naturalness, and involvement. Furthermore, for lexical causatives the four parameters include transitivity, intention, naturalness, and control. Based on the overall data analysis, it is known that the formation of causatives in Kuto-Kute semantically involves five semantic parameters, namely transitivity, naturalness, intention, involvement, and control.

$\begin{array}{llllll}\text { 1SG } & \text { first person singular } & \text { 3SG } & \text { third person singular } & \text { A } & \text { Agent } \\ \text { ACT } & \text { active } & \text { APPL } & \text { applicative } & \text { AV } & \text { Actor Voice } \\ \text { CAUS } & \text { causative } & \text { DEF } & \text { definite } & \text { O } & \text { Object } \\ \text { POSS possessive } & \text { S } & \text { Subject } & & \end{array}$

\section{REFERENCES}

[1] Baker, Mark C. (1988). Incorporation: A Theory of Grammatical Function Changing. Chicago: The University of Chicago Press

[2] Comrie, Bernard. (1985). "Causative Verb Formation and Other Verb-deriving Morphology". In: Shopen, Timothy (ed.) Language Typology and Syntactic Descripition, Vol. III. Cambridge: Cambridge University Press, 309-348.

[3] Dixon dan Aikhenvald. (2000). Changing Valency: Case Studies in Transitivity. Cambridge: Cambridge University Press.

[4] Dixon, R.M.W. (2000). "A typology of causatives: form, syntax and meaning." In: Dixon, R.M.W. \& Aikhenvald, Alexandra Y. (eds.) Changing Valency: Case Studies in Transitivity. Cambridge: Cambridge University Press, 30-83.

[5] Dixon, R. M. W. (2012). Basic Linguistic Theory. Volume 3: Further Grammatical Topics. Oxford: Oxford University Press.

[6] Frawley. (1992). Linguistics Semantics. New Jersey: Lawrence Erlbaum Associates Publisher.

[7] Goddard, C. (1998). Semantic Analysis: A Practical Introduction. Oxford: Oxford University Press.

[8] Haspelmath, Martin. (1993a). A grammar of Lezgian. Berlin: Mouton de Gruyter

[9] Haspelmath and Müller-Bardey. (2001). Valency change. https://www.eva.mpg.de/fileadmin/content_files/staff/haspelmt/pdf/ 2005val.pdf (accessed 10/1/2020).

[10] Malchukov, Andrej and Bernard Comrie. (2010). The Leipzig Valency Classes Project's Database Questionnaire Manual. http://valpal.info/public/valencydbquestionnaire manual.pdf (accessed 26/5/2018).

[11] Shibatani, M. (ed.) (1976b). The Grammar of Causative Constructions (Syntax \& Semantics 6). New York: Academic Press.

[12] Song, Jae Jung. (1996). Causatives and causation. London \& New York: Longman

Nurul Azizah is currently a doctoral student studying in Udayana University, Bali, Indonesia. She accomplished her undergraduate degree in 2005 from Mataram University and Master Degree in 2011 from UHAMKA, Jakarta, both majoring in English.

Ketut Artawa is a professor in Linguistics at Udayana University, Bali, Indonesia. He received his Master Degree in Linguistics from La Trobe University in 1992 and got his Doctorate also from La Trobe University in 1995. His research interests involve a wide range of topics on morpho-syntax and linguistic landscape.

Ni Luh Ketut Mas Indrawati is a senior lecturer in Udayana University Bali, Indonesia. She accomplished her MA in Applied Linguistics in 1994 from Sydney University and her PhD in 2012 in Linguistic Typology from Udayana University. Her research interests are linguistic typology, sociolinguistics and applied linguistics.

Made Satyawati is a lecturer at Udayana University, Bali, Indonesia. She received her Master Degree in Linguistics from Padjadjaran University, Bandung, Indonesia in 1999 and got her Doctorate Degree in Linguistics from Udayana University in 2010. Her research interest falls into linguistics, namely syntax and semantics. 